\title{
Alfonso Reyes. Su itinerario y deslinde filosófico
}

\author{
Virginia Aspe Armella
}

$\mathbf{P}$ ara esta investigación formulé una pregunta: ¿es Alfonso Reyes un filósofo? La hipótesis es poco ortodoxa, la tradición alfonsina lo ha reconocido como humanista y hombre de letras, alguien que tuvo como quehacer la palabra, tanto en su perspectiva filológica como en el ámbito poético. Reyes mismo se decía poeta y si en algún campo, esa personalidad sólida, madura, con inteligencia fría y erudita, se encontraba insegura, fue precisamente en la filosofía.

Aunque trabajó dirigiendo filósofos, impartió cursos en la Facultad de Filosofía y Letras, comentó y leyó obras filosóficas clásicas y contemporáneas de gran envergadura $;{ }^{1}$ se sabía de su voracidad filosófica ${ }^{2}$ además de que muchas de sus obras dieron también lugar a discusiones filosóficas, ${ }^{3}$ Reyes nunca se denominó un filósofo y la crítica de su obra tampoco ha dado en llamarlo así. Pienso que ello se debió a que su labor literaria eclipsó sus otras actividades. Su virtuosismo literario y poético desbordó el discurso académico, discurso filosófico donde él mismo se había mostrado menos confiado. Aunque de hecho hubo quien sí logró entrever que Alfonso Reyes fue filósofo.

En un escrito de 1960 titulado "Alfonso Reyes el escritor", José Gaos dice que: "El deslinde es donde llegó a tener plena conciencia filosófica". ${ }^{4}$ Esta obra, escrita al final de su vida, representa, en mi opinión, la plena madurez

${ }^{1}$ Entre ellas, los Diálogos de Platón, la Poética, Física y Del alma de Aristóteles, obras de Nietzsche, Husserl, Heidegger y Schopenhauer.

2 "Mi querido Gaos, ya devuelvo a Morelia los 15 volúmenes de Nietzsche y Schopenhauer" ("Carta del 2 de mayo de 1941", en Alberto Enríquez Perea, comp., Itinerarios filosóficos: correspondencia José Gaos/Alfonso Reyes, 1939-1959. Presentación de Andrés Lira. México, El Colegio de México, 1999, p. 95).

${ }^{3}$ Sobre su obra El deslinde recibió comentarios de Werner Jaeger, Ingermar Düring, Ermilo Abreu Gómez, Edmundo O'Gorman y Alfonso Méndez Plancarte, entre otros.

${ }^{4}$ A. Enríquez Perea, comp., op. cit., p. 223. 
del pensamiento alfonsino. Tiene otros escritos teórico-literarios: La crítica en la edad ateniense, La antigua retórica y La experiencia literaria. Esta última rastreando las coordenadas del saber literario, pero en El deslinde, Reyes llega a hacer ya "filosofía a secas".

Obra antilírica -el calificativo es de José Gaos-, muestra cómo Reyes pensaba escribiendo y al escribir pensaba, porque como decía Gaos "escribir por escribir es una tarea intelectual aunque Reyes se denominara poeta". Algo pasó después de la publicación de $E l$ deslinde que frenó el desarrollo filosófico alfonsino, obra que "en su día fue exaltada y vituperada, al correr de los años, que remansan la opinión, se fue perfilando como una de las obras mayores del pensamiento hispanoamericano", ${ }^{6}$ pero en su día se le hicieron serias objeciones: que usaba mal el término fenomenología o que, al menos, no seguía la noción de Husserl en este sentido. Inseguro, cambió el término en esta obra y en las anteriores que lo utilizaban por "fenomenografía". A Gaos le pareció una obra precipitada, realizada con excesiva rapidez. Reyes meditó mucho sobre esa polémica e intentó contestar a sus críticas con su obra final Al yunque; en ella sostiene que ha intentado analizar el fenómeno literario de la misma manera en que lo hizo Aristóteles, de las partes al todo, y que quizás no lo habían comprendido. Pero lo cierto es que $E l$ deslinde dio lugar al gran ciclo de conferencias del Colegio Nacional en tiempos de Reyes y que después fue libro de texto durante la cátedra Agustín Yáñez de la Facultad de Filosofía y Letras de la UNAM. El tema de El deslinde es el del objeto literario frente a los otros objetos teóricos del espíritu; con esta temática, al igual que la Poética de Aristóteles, su obra aparecería como algo a caballo entre especialistas de filosofía y de letras.

Me parece que es allí donde la labor filosófica de Reyes comenzará a ser mal entendida. En la mentalidad moderna filosófica de mitad del siglo xx en México, que es heredera de la Ilustración y del positivismo para optar después por la filosofía analítica donde sólo el que es un "scholar" es un filósofo de verdad, el tema de $E l$ deslinde aparece como la filosofía del autogol, pues deslindar es la tarea de separar, abrir huecos o vacíos, rupturas, brechas e indefiniciones, allí donde el ilustrado y el analítico purista exigen especificidades y significaciones.

Reyes no fue comprendido como filósofo porque se anticipó a su tiempo, allí donde se buscaba especulación y argumentaciones noéticas, el regiomontano se propuso reflexionar sobre las diferencias y las demarcaciones. El deslinde no es el título de una obra sino un género filosófico que instauró anticipan-

${ }^{5}$ Ibid., p. 225.

${ }^{6}$ Ernesto Mejía Sánchez, "Nota preliminar", en Alfonso Reyes, "El deslinde", en Obras completas. México, FCE, vol. XV, 1997, p. 7. 
do un nuevo modo de hacer filosofía, filosofía de fronteras, en donde el método consiste precisamente en separar; filosofia de la diferencia, algo que hoy nos resulta familiar por el discurso filosófico de un Vattimo, Derridá, Lyotard o Foucault, pero que en los años cuarentas del siglo pasado era aún inimaginable. En Reyes se instaura un nuevo género filosófico donde el objeto material no es el ser sino la literatura, teniendo como sentido la ficción, la intención y el empréstito. Si el ser griego estaba validado por el tema de lo en sí y del hogar, el género filosófico alfonsino se inserta en lo medial, lo relativo y metafórico, se estudia la ficción y la verosimilitud poética.

En su tiempo este tipo de filosofía no podía ser comprendida porque no existía. Realmente la tarea de Reyes en este campo fue poco ortodoxa e incluso a un visionario como José Gaos le costó entenderlo. Gaos calificó la labor alfonsina de "filosofía de fronteras" por la variedad de géneros y por el modo de realizarla: "escritos de escritos" en una "dualidad de facultades" que anticipan que es "conciencia de sí". 7

Pero vayamos más despacio: comencemos por dar algunos datos de la inteligencia y vocación filosófica de Reyes a través de su correspondencia, esa relación epistolar que puede dejarnos algo de su biografía intelectual, si es que realmente vale la pena, pues en mi opinión, la producción epistolar de Reyes con los hombres de su tiempo es válida si de ella aparece realmente la biografía intelectual de nuestro autor. No basta con compilar pequeñas notas marginales, recados, peticiones accidentales - una tesis de $E l$ deslinde que él siempre defendió es que lo accidental es irrelevante si no conecta con el entramado lógico de toda una vida. Comencemos como don Alfonso lo hacía en sus escritos, de la correspondencia más simple a la más profunda, para rescatar mejor su vocación y tarea de filósofo.

Si entendemos la correspondencia de Reyes como "el apunte oportuno -más o menos formal, según la ocasión- con el que procuraban ceñir la actividad desbordante, la tarea realizada y pendiente en el incesante quehacer intelectual", ${ }^{8}$ encontraremos datos claves que forjaron su talante filosófico. A don Alfonso le configuró su inteligencia el haber sido miembro del servicio diplomático mexicano. Ese oficio no sólo lo refinó más en sus modales y maneras facilitándole relaciones culturales extranjeras de primer orden, sino que moldeó su inteligencia de un modo más institucional y frío, desapegado del impulso emocional que tanto le jalaba por la palabra poética, dándole pausa y reflexión, y una experiencia universal de talante filosófico. El haber sido después, desde 1939, presidente del Patronato de la Casa de España en

\footnotetext{
${ }^{7}$ A. Enríquez Perea, comp., op. cit., pp. 217-234.

${ }^{8}$ Andrés Lira, "Presentación", en ibid., p. 13.
} 
México y que ese nombramiento se lo hubiese dado un presidente de México -Lázaro Cárdenas- institucional, corporativista y con clara impronta socialista, también lo configuró. En ese cargo tuvo bajo su mando a filósofos de mayor reconocimiento que el propio. ${ }^{9}$ Reyes mantuvo sobre ellos autoridad intelectual y de gobierno, a veces, con las maneras suaves pero inclementes que había aprendido de la fría diplomacia; por ejemplo, en carta del 19 de junio de 1939 escribe a Gaos: "Está en mis manos el programa de su curso y seminario sobre Marx y Nietzsche que usted tuvo la bondad de entregar a Daniel Cosío. Le agradeceré a usted que, en cuanto le sea posible, nos envíe traducciones de textos indispensables, así como las fechas convenientes para el desarrollo de su curso". ${ }^{10}$ Permítame el lector reestructurar este argumento diplomático al modo en que lo interpreta una filósofa como yo: "Señor Gaos, me ha entregado usted su curso y seminario sobre Marx y Nietzsche sin fechas y sin el material con el que estudiarán los alumnos, pues ellos no hablan la lengua vernácula de los autores y textos que usted propone”. Otra carta posterior, es la del 13 de abril de 1940 al mismo José Gaos: "Revisando nuestros anteriores planes, parece llegado el momento de que se sirva usted indicarnos, con toda aproximación posible, la fecha en que podría usted entregarnos las obras que de meses atrás nos tiene ofrecidas sobre teoría y didáctica de la filosofía de Heidegger. Agradeciendo su pronta respuesta, su amigo. Alfonso Reyes". ${ }^{11}$

La transcribo y reestructuro desde mi óptica noética: 1. Señor Gaos, lleva usted meses de retraso con el texto que prometió entregar sobre la filosofía de Heidegger. 2. Señor Gaos, no divague, deme la fecha exacta de entrega de su libro atrasado hace meses. Por último, Reyes hace una delicada y diplomática corrección a un escrito de José Gaos donde dice:

No encuentro texto griego del pasaje de Platón que nos interesa. Aparece en el libro III de Las Leyes, poco antes de la cita de Píndaro. Otra traducción distinta de la que seguí hace decir al "ateniense" que las cosas de mayor ignorancia son las siguientes: "cuando juzgando que una cosa es bella y buena, en vez de amarla se le toma en aversión; o cuando se ama y adopta lo que se reconoce malo o injusto". Casi es seguro que el texto griego dice "amar" en vez de "gustarme". ${ }^{12}$

${ }^{9}$ Bajo su mando estuvieron José Gaos, Luis Villoro, Samuel Ramos, Leopoldo Zea, Fernando Salmerón, Carmen Rovira, Vera Yamuni, Alejandro Rossi, Edmundo O'Gorman, etcétera.

${ }^{10}$ A. Enríquez Perea, comp., op. cit., p. 44.

${ }^{11}$ Ibid., pp. 71-72.

${ }^{12}$ Ibid., p. 89. 
Mi interpretación del escrito: señor Gaos, usted tradujo erróneamente el pasaje de Leyes III de Platón donde después de la cita de Píndaro puso "gustar" en lugar de "amar".

La correspondencia entre Gaos y Reyes manifiesta no sólo este talante diplomático y virtuoso que todo director tendría que mostrar al dirigirse a sus subalternos, sino el señorío, la autoridad y mando que el presidente de la Casa de España había desarrollado para sacar lo mejor de cada uno de sus académicos. En su vida social, y con esos mismos intelectuales, Reyes fue siempre reconocido como alguien afectivo y acogedor; pero el puesto de director le había exigido otro modo de enfrentar a sus colegas. Este vaivén en su personalidad y su afán literario fue forjando su capacidad filosófica. José Gaos admiró y comprendió su obra, aunque nunca por completo. En su análisis sobre $L a$ crítica de la edad ateniense nos dice Gaos: "tan de corazón era Reyes aficionado de Grecia como penetrante intérprete de las obras de su cultura... Pero ese motivo se revela englobado en una motivación mucho más amplia, profunda, significativa. De la palabra oral, nació segundona la escrita, mas para acabar disputando a la hermana el mayorazgo". ${ }^{13}$

Para Gaos, Reyes fue un intelectual sui generis desde la perspectiva filosófica. El transterrado consideraba al hombre de letras un hombre de ideas y de imaginación y para él, Reyes encarnaba al grupo humano de aquellos que conjuntaron lo personal con lo histórico y lo literario en Hispanoamérica. Sostuvo que Reyes había logrado pasar de las letras "a la reflexión sobre la literatura y el escribir mismos, sobre la propia actividad, pero como forma de vida y hasta el fondo último de esta forma". ${ }^{14}$ Fue Gaos y después su discípulo Fernando Salmerón quien rescató el término alfonsino de jornadas. Nos dice Gaos: "nueva jornada, la de la reflexión - no ya ocasional ni marginal, sino temática y sistemática- sobre su oficio, en el sentido y con el alcance indicado: filosofía de la literatura".

Pero después lo denomina, ya no filósofo - filósofo de la literatura-sino un "prefilósofo" por aunar ciencia, filosofía de la literatura, filología, historia de la literatura, ser poeta y escritor. Quizás a Gaos le sucedieron dos cosas: por un lado, valoró, y en mi opinión lo hizo bien, que la obra literaria de Reyes desbordó y eclipsó su filosofía, por otro, pienso que Gaos no comprendió cabalmente el profundo sentido filosófico aristotélico con que Reyes desarrolló su Itinerario filosófico de El deslinde: la noción de universal.

Se lo reiteraba Reyes molesto: "universal no es descastado"; es decir, no planteaba una filosofía universal desde la perspectiva cuantitativa, intensificaba su exploración en el nivel de la cualidad. Reyes realizó un modo de abstracción

${ }^{13}$ Ibid., p. 200.

${ }^{14}$ Ibid., p. 201. 
filosófico sobre el fenómeno literario desde el punto de vista intensivo; pero, como escritor y humanista, los ejemplos que daba en esa penetración metódica los daba a la luz de la cultura y muchos de sus colegas no acabaron de comprender esa forma y nivel de discurso. Por ejemplo, en su escrito "México en la obra de Reyes" la disertación de Gaos sobre la "x" en la frente de Reyes no alcanza el sentido profundo que el regiomontano le había dado. Don Alfonso logró acuñar en una sola letra, y por cierto, la más indefinida en su uso, la $\mathrm{x}$, todo el drama y el carisma de una cultura y nacionalidad. Tal era el profundo sentido del universal que había tomado de Aristóteles en Analíticos posteriores.

Precisando esta noción de universal, clave de su filosofía, decía "La única manera de ser provechosamente nacional consiste en ser generosamente universal, pues nunca la parte se entendió sin el todo". ${ }^{15}$ Él mismo en la formulación de su propia filosofía separa la noción cuantitativa de universal cuando dice: "tomo de Toynbee el tema de la cuantificación de los datos en el tema de la escala que desarrollo, pero debo hacer notar que Toynbee no tomó en cuenta el universal cualitativo". ${ }^{16}$ Y es que, insisto, Reyes se anticipó a un nuevo modo de hacer filosofía porque consideraba que "la ficción es el modo más cabal de verdad", que la literatura es la manifestación "más universalmente humana", ${ }^{17}$ al decir esto, hacía filosofía a secas porque el eje transversal en que desarrolló su tesis filosófica fue la intención, noción que concebía no como una noción ética sino noética. ${ }^{18}$ Filosofía de la ficción, de la verosimilitud. Reyes tiene un enfoque colateral del suceder real y del ente porque descubre suficiencia en el suceder ficticio y así, desde el noema, se adentra en la realidad del poema. Ésa es la peculiar entidad filosófica que instaura. Tiene la convicción de que la filosofía y la literatura captan más el universal cuantitativa y cualitativamente ${ }^{19}$ y aunque acepta que en filosofía la mayor virtud es la coherencia lógica ${ }^{20}$ estira la liga de esta sentencia para decir que de esto "la mayor flexibilidad posible está en la poesía". ${ }^{21}$

15 Ibid., p. 207.

${ }^{16}$ A. Reyes, "El deslinde", en op. cit., p. 147.

${ }^{17}$ Ibid., p. 178.

${ }^{18}$ Ibid., p. 168.

${ }^{19}$ Cf. ibid., p. 185.

${ }^{20}$ De clara lectura aristotélica.

${ }^{21}$ A. Reyes, "El deslinde", en op. cit., pp. 185 y ss. He disertado este tema del criterio aristotélico de congruencia lógica de la filosofía en "Verdad y verosimilitud en la filosofía de Aristóteles", en Perennidad y apertura de Aristóteles: reflexiones poéticas $y$ de incidencia mexicana. México. Ed. Cruz. 2005. 
Tengo la hipótesis de que la Poética de Aristóteles fue la obra que formó intelectualmente a don Alfonso. La conoció y analizó desde que era muy joven, ${ }^{22}$ es hilo conductor tanto de la Crítica en la edad ateniense como de El deslinde. Respecto de esta última, los pasajes alfonsinos en torno a que la poesía es más filosófica que la historia, son contundentes para el ulterior desarrollo de su filosofía de la literatura. ${ }^{23}$ A lo largo de sus escritos, notamos que conoció distintas traducciones y ediciones de la Poética ${ }^{24}$ Es de esta obra de donde Reyes extrae el punto de partida de su peculiar creación filosófica. La cuestión que toma de allí, del pasaje citado de la Poética que hace la distinción y supremacía filosófica de la poesía frente a la historia, es punto de partida hacia su idea de que "la literatura capta de una sola vez el universal humano". ${ }^{25}$ Pero Reyes no hace filosofía al modo aristotélico ni comparte los principios literarios del de Estagira en modo absoluto. Toma de él la noción literaria de unidad de acción, su sentido de universalidad poética y la peculiar modalidad lógica que instaura.

"Aristóteles habla de una lógica interior del poema en el que ve un reflejo de cierta lógica fundamental del espíritu, pero no de una lógica con apego al suceder real" ${ }^{26}$ La clave está en la intención -nos dice don Alfonso-, lástima que Aristóteles enfatizó tanto en la mimesis complicando la nitidez de muchas de sus soluciones, pues la libertad y la intención no obstan para la universalidad poética. Me parece que es desde esta vía de la Poética de Aristóteles de donde arranca nuestro autor para, formalmente a raíz de la página 192 y delante de $E l$ deslinde, instaurar un nuevo modo de hacer filosofía. Las páginas previas habían sido -según Reyes- "un prolegómeno a lo que él verdaderamente intentaba realizar en su obra”.

Sólo hasta el capítulo cuatro de su segunda parte, titulado "Ficción literaria", Reyes sostiene su propuesta: "la coronación filosófica es la ficción, la punta de la pirámide", pues el estudio de la ficción nos transporta al ser mismo de la literatura. ¿Cuál es pues para Reyes esta peculiar filosofía de frontera que incluye la historia, la ciencia, la sociedad, las ciencias del espíritu y la literatura, y que parece ser la cúspide de su reflexión?: "La humanización total es por la literatura". ${ }^{27}$

${ }^{22} C f$. Virginia Aspe Armella, "Contribuciones alfonsinas para acceder a una adecuada hermenéutica de la Poética de Aristóteles”, en Ulises Sánchez y Minerva Villarreal, comps., Góngora y la tradición clásica. México, Los libros de Homero, 2007, pp. 93-105.

${ }^{23}$ A. Reyes, Obras completas, vol. XIII, p. 182. Allí remite al mismo tema y a Aristóteles en su Crítica de la edad ateniense, pp. 472 y ss.

${ }^{24} \mathrm{En}$ El deslinde refiere a la edición de Joseph Goya y Muniain de 1798.

${ }^{25}$ A. Reyes, "El deslinde", en op. cit., p. 185.

${ }^{26}$ Idem.

${ }^{27}$ Ibid., p. 190. 
En una operación y abstracción intensiva cuyo fin es el ser de lo literario, Reyes ha pasado de la historia, como suceder efímero de lo humano, a las ciencias exactas: físicas y naturales, extrahumanas por su asunto, de allí a las ciencias del espíritu y, de éstas, a la literatura. Pero el lector debe de tener aquí mucho cuidado de no malinterpretar la operación intensiva de Reyes; no se trata de un proceso de abstracción formal donde paulatinamente se vayan excluyendo las particularidades de los objetos que se estudian, ni de una abstracción total al modo existencial de la filosofía medieval tomista que intensificaba la operación desde el singular, manteniendo al ser real por reflexión del singular en metafísica. ${ }^{28}$

He aquí la novedad y complejidad de la tarea filosófica de lo literario en Reyes: se trata de una reflexión límite, de límites y fronteras que tocan el suceso interior $-\mathrm{y}$ no digo que el punto de partida sea la conciencia-, Reyes ni es idealista, ni romántico, tampoco propone una filosofía racionalista, sino algo "naturalmente literario" para decirlo con un binomio contradictorio que expresa cabalmente su esfuerzo y asunción, porque "el suceso interior no acontece autonómicamente sino que viene transportado y teñido en un flujo mental que lo sustenta, en una intención. La intención obra de emoliente en la correspondencia y tiende a borrar sus fronteras". ${ }^{29}$

Se trata de un proceso dual entre lo cualitativo externo y la intención, un grado más alto e intensivo que además es diverso porque tiene como objeto un ser que no posee fundamento ni es natural, un esse poemático al que sólo se accede desde las fronteras mismas de las actividades del espíritu. Se trata de pasar por el desfiladero alto y muy angosto que queda entre las actividades teóricas, rozándolas colateralmente. Reyes no quiere correspondencia y menos adecuación con ellas, entiende que algo de empréstito ocurre en ese pasar de cerca por su lindero, pero que la ganancia es la sola mediación y la colateralidad. El ser literario es medial, correlativo, su naturaleza es no ser natural, no es algo en sí mismo, el ser de la literatura está en la posibilidad. ${ }^{30}$

${ }^{28}$ Por ejemplo, vemos esta propuesta y este deslinde de modos de abstracción en Tomás de Aquino, Comentarios a la Trinidad de Boecio.

${ }^{29}$ A. Reyes, "El deslinde", en op. cit., p. 167.

${ }^{30}$ Para esclarecer este asunto creo que habría que rastrear más la liasson Alfonso Reyes-sor Juana Inés de la Cruz. Sabemos que la estudió, que se ocupó profundamente de su poesía (en correspondencia Manuel Toussaint-Alfonso Reyes, en la carta del 26 de febrero de 1941 le pide a Toussaint datos sobre la autenticidad de un villancico de ella y la cuestión de los negros por sus tocotines y en sus diversas obras sobre crítica literaria es recurrente la mención de la obra de la Jerónima).

El poema "Primero sueño" le había dejado pasmado, porque igual que su propuesta es un poema escrito en blanco y negro y que toca las fronteras del nous aunque en sor Juana verdad filosófica, forma de discurso en verso, significado y metáfora se encarnan 
En el fondo, lo que nos dice Reyes de su propuesta es que la teoría literaria requiere de prolegómeno una filosofía de la literatura. La propuesta filosófica alfonsina es un deslinde previo a la crítica literaria porque "no cabe la reconstrucción de un autor o texto literario sólo por el texto literario" se trata de un prolegómeno filosófico.

Desde sus veinte años, Alfonso Reyes ya había sostenido esta propuesta; en ocasión de la Poética de Aristóteles, había dicho que no era una obra filosófica sino una crítica y análisis de lo poético que suponía conocimientos profundos de la filosofía de Aristóteles. Ahora, en la madurez, Reyes hace una propuesta filosófica a su manera, pero igual al Itinerario de la Poética de Aristóteles: que una teoría literaria supone toda una base filosófica. El deslinde es quizás la obra más polémica y complicada de Reyes. Escrito en 525 páginas, el texto involucra tres formas de discurso: filosófico, literario y científico tanto con digresiones delámbito de las ciencias sociales como de las naturales. Difícil por los cambios bruscos de género, el escrito recurre constantemente a confrontar proposiciones literarias -si se les puede llamar así-, científicas y de vida cotidiana como metodología. En apariencia estas últimas le restan gravedad a la profundidad filosófica; y el recurso a la filología, a la estructuración y técnicas lingüísticas, así como las digresiones de ciencia y filosofía contemporánea lo hace a veces molesto y aparentemente disperso. Para colmo, si uno intenta tomar de la obra lo verdaderamente esencial, don Alfonso nos anticipa que habremos perdido por completo el sentido, que es una obra que debe leerse de golpe y completa... en mi opinión, estamos frente a un escrito mucho más filosófico y complicado que la Poética. Desde el prólogo, el mismo Reyes se encarga de adelantarnos que aquí está la propuesta novedosa de su vida: "Nuestra América, heredera hoy de un compromiso abrumador de cultura y llamada a continuarlo, no podrá arriesgar su palabra si no se decide a eliminar al intermediario".

Este hombre que tanto escribió sobre el qué y el cómo escribieron otros, aparece creador y libre en su poesía y en esta propuesta novedosa -sin intermediarios-, es decir, aquí Alfonso cede paso a los griegos, en especial a Aristóteles, para hablar por sí mismo y hacer su propuesta filosófica mexicana.

Sabía él que ésta era su obra cumbre. Auspiciada por la Fundación Rockefeller, intentaba proponer un modo de humanización de la filosofía que no se había dado: a través de la literatura. Para ello, proponía un método novedoso: filosofía desde las diferencias, ejerciendo deslindes. Divide la obra en tres partes precisas: en la primera se pregunta qué es la poesía literaria, anuncia la metodología del libro y acuña su nueva terminología filosófica: la función ancilar,

en un poema, $E l$ sueño, mientras que en Alfonso Reyes, El deslinde es efectivamente filosofía a secas. 
la cuestión de los empréstitos en los deslindes, etcétera. En la segunda parte realiza su primer deslinde o "primera tríada de las ciencias teóricas: historia, ciencias de lo real, literatura, vistas desde la cantidad, la cualidad hasta llegar a la ficción o deslinde poético. En la tercera y última parte realiza su análisis de la segunda tríada teórica: matemáticas, teología y literatura. Este segundo modo de acceso es a la luz de los grados de abstracción de cada una de ellas. Algo he anunciado en mi introducción al respecto, pero por motivos de espacio, en esta investigación expondré exclusivamente el itinerario filosófico de $E l$ deslinde de la primera tríada teórica: historia, ciencia de lo real, literatura.

Reyes justifica desde el inicio de su obra que va a hacer filosofía de la literatura: "la literatura es un cambio entre una postura activa y una pasiva", ${ }^{31}$ donde la activa supone una intención y la pasiva refleja exclusivamente las leyes y los modos de algo.

Rechaza estar en el terreno de la ciencia de la literatura, que la hay y él la hace, filología, psicología, técnicas de estilo, historia y géneros de relatos.

Declara que va a hacer y proponer una filosofía, dice textualmente: "la teoría literaria es un estudio filosófico y propiamente fenomenográfico". ${ }^{32}$ Ubica el centro de su disertación en la dimensión teórica: "la teoría es la contemplación más desinteresada frente a la postura activa y en su totalidad, entendida ésta como rumbo mental, como sesgo noético con contenido noemático, como agencia del espíritu".33

Después justifica el objeto del deslinde:

1. El primer paso para la teoría literaria es establecer el deslinde entre lo literario y lo no literario, pues se intenta hacer filosofía de algo que no es objeto de la filosofía.

2. Para ello, hay que fijar las coordenadas, ni entrar aún en la intimidad literaria ni hacerla fijar sus coordenadas, sólo ir al contorno, no a las estructuras.

3. Por último, establecer la metodología a seguir: "hacer una fenomenografía del ente fluido". ${ }^{34}$

Se da cuenta de la dificultad y del drama que se propone, dice "éste es un viaje a las regiones indecisas” donde no habrán conclusiones sólo tendencias, aproximaciones. ¿Se anticipa Reyes al salto posmoderno de filosofías nihilistas? El análisis de fronteras alfonsino no queda en la nada, entre las esencias, sino

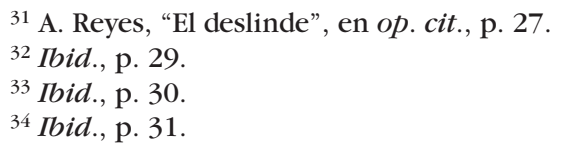


en preguntarse qué puede pasar y cómo es eso de estar fuera de ellas. Si la filosofía griega y medieval habló del ente y del logos, Reyes se plantea qué queda fuera del ente y del logos: el ser de la ficción. Si otros autores que disertan sobre poesía, filosofía y lo sagrado, como Ramón Xirau, por ejemplo, responden desde la presencia, Reyes responde desde las fronteras. Para él, la tarea filosófica por excelencia debe ser ésta: ejercer actividad de fronteras, "avanzar como el samurai con dos espadas, nuestra atención se divide en dos series de observaciones paralelas, lo literario y lo no literario; el movimiento del espíritu, y el dato captado por ese movimiento, la noética o curso de pensar y la noemática o ente pensado" ${ }^{35} \mathrm{El}$ desfiladero, el entre, no es sólo de las actividades del espíritu, ello sería formalmente filosófico y ya lo había dicho Aristóteles al distinguir lo teórico de lo práctico y de lo poético; el esfuerzo alfonsino está entre las demarcaciones que hay en las actividades y lo que queda entre la intención y el pensar. Nos previene: "la naturaleza misma del objeto literario puede producir confusiones en las doctrinas más sublimes". ${ }^{36}$ De ella han surgido dos ideas inconciliables: una platónica, la inspiración, la otra aristotélica, la expresión de una realidad. Reyes sostiene que su teoría literaria nació con Aristóteles, pero con una confusión de origen, pues el estagirita la hizo con un deslinde entre el uso técnico y el uso vulgar de la palabra que ató la realidad al punto de partida de la mimesis ${ }^{37}$ cayendo en cierto naturalismo. Para Reyes, toda obra de creación humana, desde Sócrates en el Simposio de Platón, acontece con poesía. ${ }^{38}$ Es esta consideración técnica del lenguaje la que establece el derecho de uso de la metáfora, el derecho de uso de términos en sentido traslaticio, el derecho de uso de palabras con intención. He aquí la propuesta: el lenguaje poético, o mejor dicho en Reyes, el lenguaje literario -porque la palabra literatura abarca todas las formas poéticas- es un derecho humano. Si por la inteligencia el lenguaje tiene una connotación semántica o de significados, hay una manera verbal, una agencia especial del espíritu que cuaja en obras literarias no como función o correspondencia entre la facultad y el contenido que ésta ha adquirido en la operación, porque carece de connotación alguna aunque puede involucrarla: "toda mente opera literariamente sin saberlo". ${ }^{39}$ Literatura es todo signo mental, verbal o escrito. La función literaria tiene tal universalidad que en sus orígenes se ha confundido siempre con las

35 Ibid., p. 32.

${ }^{36}$ Ibid., p. 33.

${ }^{37}$ En mi opinión nuevos estudios sobre el concepto de mimesis en Aristóteles salvan esta interpretación alfonsina. $C f$. V. Aspe Armella, El concepto de técnica, arte y producción en Aristóteles. México, FCE, 1994.

${ }^{38}$ Platón. Diálogos. Simposio o del amor, 186a-205c.

${ }^{39}$ A. Reyes, "El deslinde", en op. cit., p. 43. 
fronteras de las supersticiones, el folclor y la mitología. ${ }^{40}$ Pero al ir depurando lo literario se vislumbran paulatinamente las fronteras: el conocimiento de la esencia absoluta es la teología, el estudio del ser y de la realidad es la filosofía, la historia y las ciencias estudian el suceder, la primera, el suceder efímero, las segundas el suceder en sus leyes y regularidad. En cambio, la teoría literaria estudia el fluir de la actividad teórica expresando sus propias creaciones.

Hasta aquí alguien podría preguntar por qué Reyes no abrazó la actividad teórica filosófica si lo que está haciendo es filosofía de la literatura, pero allí radica precisamente la original contribución de Reyes, descubre que entre la filosofía y la literatura se abre un hito, un espacio insalvable que tiene que conectar: "la filosofía, como disciplina específica, es perfectamente discernible pero como movimiento teórico ella es el instrumento del deslinde entre lo histórico, lo científico y lo literario; y hay que tener en cuenta que "la vara de medir" no se mide a sí propia. La filosofía no puede deslindarse porque ella misma es aquí la operación del deslinde". ${ }^{41}$ Pensar en la distinción de las obras y producciones es pensar filosóficamente, es así que el criterio del deslinde no puede figurar porque el deslinde mismo es una operación.

La literatura aparece como operación filosófica rebasada por sí misma, desborda aquello que le precede, la tarea filosófica. "La literatura no conoce límites noemáticos ni admite contaminaciones noéticas". ${ }^{42}$ La literatura es inflexible en la intención al mismo tiempo que se vuelve ilimitada en sus motivos. Se define por la pureza de su sentido a la vez que por la universalidad de motivos.

Reyes caracteriza la literatura después de haber encontrado esta operación: la literatura es integradora. Integradora de todos los motivos e intenciones; es integración de la no literatura y vive de ello porque al no ser algo en sí ejerce empréstitos constantes de campos ajenos. Pone el ejemplo de sor Juan Inés de la $\mathrm{Cruz}^{43}$ que aborda literariamente la teología con la teoría musical. Al ser ambos órdenes -teología y música- incomunicables surge la excitación metafórica en su escrito.

La sobreabundancia de la operación literaria o poemática frente a los órdenes teóricos de la mente instaura un nuevo modo de lenguaje. Así, de la filosofía y la crítica, Reyes cede paso al análisis poemático y a la creación literaria.

Una anécdota documentada por Claude Fell ${ }^{44}$ en la correspondencia entre Reyes y Vasconcelos nos muestra cómo don Alfonso fue cediendo paso

${ }^{40}$ Ibid., pp. 55-70.

${ }^{41}$ Ibid., p. 80.

${ }^{42}$ Ibid., pp. 107 y ss. En estas páginas está la peculiar teoría del conocimiento literario de Reyes.

${ }^{43}$ Ibid., p. 112.

${ }^{44}$ Claude Fell, Ecrits oubliées. Correpondance José Vasconcelos et Alfonso Reyes. Institute Français d'Amerique Latine, 1976, p. 53. 
paulatinamente al análisis literario después de penetrar más en la filosofía de la literatura, o, dicho con palabras de Gaos, esta anécdota nos muestra que al paso del tiempo fue verdad que en Reyes la hermana menor -la palabra escrita- quitó el lugar a la mayor, pero sólo después de priorizar la primera.

Al comentar a Vasconcelos su reencuentro con Manuel Toussaint, un joven crítico de arte mexicano que prometía ser grande, Reyes le dijo: "Me desilusionó, me pareció algo indefinido", "no sabe dibujar", lo vi "falto de deseo de ponerse en contacto con nuevos objetos, con una sociedad nueva", "con un mundo distinto", lo sentí "demasiado maleable", le hace falta aún "pensar por cuenta propia”, no encontré en él la confrontación que yo esperaba”. ${ }^{45}$ En valoraciones como éstas, ya se ve al Reyes creador de teorías: su criterio de valoración es la independencia y novedad.

En cambio, otra carta entre Toussaint y Reyes es testigo de cómo don Alfonso lo fue apreciando con el tiempo, invitándolo incluso a representar a México en el Congreso Panamericano de Historia, ${ }^{46}$ entonces, en que ya lo trata de igual, le hace una confidencia que muestra su inseguridad filosófica:

"Ermilo está haciendo contra mí en El Nacional no sé por qué motivo: acababa yo de recibir una carta de él, llena de amistad y confidencia... donde se quejaba que la crítica no había sido benévola con sus tablas de literatura, imploraba mi benevolencia al recibirlas y juzgarlas y me pedía para su sor Juana y su Alarcón buena crítica, y luego... ¡cataplún! Me encuentro los artículos confusos y torcidos, mal intencionados e iracundos, ¿qué sucede?, ¿está loco?”

En realidad, si una obra dio pie a polémica entre Reyes y sus contemporáneos fue El deslinde. Abreu mismo le había dedicado mucha tinta al respecto y pienso que otros como Méndez Plancarte, O'Gorman, Jaeger y Düring contribuyeron a que dicho texto forzara a Reyes a depurar su teoría. En mi opinión queda mucho por investigar de Alfonso Reyes en este ámbito de la filosofía.

${ }^{45}$ Serge Zaitzeff, comp., "Introducción", en Correspondencia entre Manuel Toussaint y Alfonso Reyes: De casa a casa. México. Colegio Nacional, 1990. p. 12.

${ }^{46} \mathrm{Cf}$. ibid., p. 67. Una carta de Reyes a Xavier Icaza nos amplía el suceso: Carta de Alfonso Reyes a Xavier Icaza. Carta desde Buenos Aires, 10 de febrero de 1937. Ermilo Abreu Gómez: "Alfonso Reyes. Idea política en Goethe", 5 de octubre de 1937. 